\title{
DINÂMICA DA DISTRIBUIÇÃO DIAMÉTRICA DE BRACATINGAIS NA REGIÃO METROPOLITANA DE CURITIBA ${ }^{1}$
}

\author{
Sebastião do Amaral Machado ${ }^{2}$, Alexandra Consuelo de Plácido e Silva Bartoszeck ${ }^{3}$ Afonso Figueiredo \\ Filho $^{4}$ e Edilson Batista de Oliveira ${ }^{5}$
}

\begin{abstract}
RESUMO - O objetivo desta pesquisa foi estudar a dinâmica da distribuição diamétrica com relação à idade, em povoamentos nativos de bracatinga (Mimosa scabrella Benth.) localizados nos municípios da região metropolitana de Curitiba. Os dados utilizados provieram de um experimento de densidades iniciais, delineado em blocos ao acaso, constituído de cinco blocos e quatro tratamentos, perfazendo um total de 20 parcelas de $325 \mathrm{~m}^{2}$, as quais foram remedidas às idades aproximadas de 4, 5,6 e 7,5 anos. A densidade inicial sofreu redução para $2.000,4.000$ e 8.000 árvores por hectare quando o povoamento tinha 1 ano de idade. Deixou-se também uma parcela-testemunha em cada bloco, as quais não sofreram nenhum raleamento e tinham em média 25.000 árvores por hectare. Desses cinco blocos, um estava localizado na classe de sítio I, 2 na classe de sítio II e 2 blocos na classe de sítio III. Paralelamente, foram medidos os diâmetros e as alturas de todas as árvores em 124 parcelas temporárias distribuídas nos vários municípios da região metropolitana de Curitiba, representativos de povoamentos de bracatinga sob regime tradicional de cultivo e manejo, cobrindo idades de 3 a 18 anos, e as três classes de sítio. Dentre as funções de densidade de probabilidade testadas por Bartoszeck (2000), a $S_{B}$ de Johnson foi a de melhor desempenho, sendo, portanto, utilizada para a estimativa do número de árvores por classe diamétrica e por hectare e conseqüente construção das curvas de distribuição diamétrica para as inúmeras combinações de idade, sítio e densidades disponíveis. Através da observação visual das curvas sobrepostas, evidenciou-se que essas apresentaram assimetria para a direita e achatamento (curtose), com o aumento da idade. As curvas foram, então, comparadas analiticamente entre si, pelo teste qui-quadrado, o qual revelou a existência de diferenças significativas entre as curvas de distribuição diamétrica em diferentes idades.
\end{abstract}

Palavras-chave: Estrutura diamétrica, bracatinga e efeito da idade.

\section{DINAMIC OF THE DIAMETER DISTRIBUITION OF Mimosa Scabrella Benth STANDS IN THE METROPOLITAM REGION OF CURITIBA}

\begin{abstract}
The objective of this research was to study the behavior and dynamic of diameter distribution curves with respect to age, in native stands of bracatinga (Mimosa scabrella Benth) located in the metropolitan region of Curitiba, State of Parana, Brazil. The data came from a trial of densities, arranged in randomized blocks, with 5 blocks and 4 treatments, in a total of 20 plots $\left(325 \mathrm{~m}^{2}\right)$ remeasured at the approximate ages of 4, 5, 6 and 7.5 years. The initial density was reduced to 2000, 4000, 8000 trees per hectare when the stands were 1 year old. The control plots in every block, without any treatment, had in average, 25000 trees per hectare at 1 year old. From these 5 blocks, 1 was located on site class I; 2 on site class II and 2 on
\end{abstract}

\footnotetext{
${ }^{1}$ Recebido em 10.02.2005 e aceito para publicação em 05.04.2006.

${ }^{2}$ Centro de Ciências Florestais e da Madeira da Universidade Federal do Paraná, 80210-170 Jardim Botânico, CuritibaPR.E-mail:<sammac@ floresta.ufpr.br>.

${ }^{3}$ Uniandrade.

${ }^{4}$ Departamento de Engenharia Florestal da UFPR e Unicentro.

${ }^{5}$ EMBRAPA-Florestas.
} 


\begin{abstract}
site class III. Diameters and heights were also measured in 124 temporary sample plots scatered throughout several counties of the metropolitan region of Curitiba, representative of bracatinga stands under traditional cultivation and management with ages ranging from 3 to 18 years, and the 3 site classes. Among the tested distribuition functions by Bartoszeck (2000), the $S_{B}$ from Johnson was the one with the best performance, being used to estimate the number of trees per diameter class per hectare, and for constructing the diameter distribuition curves for the several possible combinations of age, site and initial density. The evolution of the distribution curves along the ages presented positive skewness and a flat distribution (Kurtosis) with the increasing age. These curves (estimated values) were compared by the chi-square test that indicated significant differences among diameter distribuition curves at different ages.
\end{abstract}

Keywords: Mimosa scabrella, diametric structure and age effect.

\section{INTRODUÇÃO}

A bracatinga (Mimosa scabrella Benth) é uma espécie pioneira de ciclo curto, vivendo no máximo até 30 anos de idade. Após a derrubada da floresta e principalmente após a queima dos resíduos, a bracatinga regenera-se em profusão, formando um povoamento quase puro, onde pode apresentar até 100.000 plantas por hectare em seu primeiro ano de vida. Tem crescimento rápido e mortalidade altíssima, tanto que aos 7 anos de idade (idade de rotação da espécie) não existem mais que 5.000 , porém normalmente 3.000 a 4.000 plantas por hectare. No processo sucessional, a bracatinga vai sendo substituída por inúmeras outras espécies. $\mathrm{Na}$ região metropolitana de Curitiba, onde cobre de 50.000 a 60.000 hectares, é manejada desde o início do século 20, sob um sistema tradicional de corte raso, queima, cultivo no primeiro ano (milho e feijão), pousio e novamente corte raso em torno dos 7 anos de idade. Esse método de manejo tradicional usado pelos produtores rurais e fornecedores de lenha, madeira para construção, varas para escoras e outros usos domésticos, necessita ser melhorado. Para que isso aconteça é necessário que se desenvolvam pesquisas de diversas naturezas, com a finalidade de conhecer melhor a espécie, seus hábitos, seu desenvolvimento e sua dinâmica com relação a diversos fatores que os afetam, inclusive no que se refere à parte da silvimetria, como é o caso no presente estudo.

Em sua dissertação, Bartoszeck (2000) desenvolveu intenso estudo investigando o uso das funções de densidade probabilística para o ajuste da distribuição diamétrica da bracatinga em diferentes fases de seu desenvolvimento, em povoamentos nativos cobrindo diversos sítios e densidades iniciais.

Diversos autores têm pesquisado o efeito de fatores como: idade, sítio, densidade e posição sociológica sobre a dinâmica da distribuição diamétrica de diferentes espécies. É sabido que o crescimento acumulativo em diâmetro tende a aumentar com o avançar da idade, melhoria do sítio, porém tende a reduzir-se com o aumento da densidade, seja ela inicial, seja presente. Já o ritmo de mortalidade natural em bracatingais nativos é muito intenso nos primeiros anos de vida do povoamento, sendo ligeiramente afetada pela classe de sítio e muito afetada pela densidade inicial. Tonon (1998) verificou que, no tratamento com redução da densidade inicial para 2.000 plantas por hectare, aos 7 anos de idade tinha aproximadamente 1.200 árvores remanescentes, o tratamento de redução para 4.000 plantas por hectare apresentou em torno de 2.000; no tratamento de 8.000 plantas por hectare, remanesceram aproximadamente 2.500; e no tratamento-testemunha (sem redução), que a um ano de idade tinha em média 25.000 plantas por hectare, aos 7 anos apresentou em torno de 3.000 árvores remanescentes por hectare.

Com o aumento do diâmetro e a redução drástica do número de árvores por hectare, as curvas de distribuição diamétrica tendem a deslocar-se para a direita e tornar-se mais achatadas à medida que o povoamento se torna mais velho, com ligeira influência do sítio. Esses efeitos foram comprovados em pesquisas de Machado et al. (1990) para plantações de Pinus taeda no Estado do Paraná e Scolforo (1990) para Pinus caribaea em São Paulo, Clutter e Benett (1965), trabalhando com Pinus elliotti nos Estados Unidos, também observaram que a distribuição diamétrica variou em função da idade, do índice de sítio e da densidade inicial.

Esta pesquisa partiu da hipótese de que a bracatinga, por ser uma espécie pioneira, heliófita e que se regenera em ciclos, formando inicialmente povoamentos quase puros, além de apresentar distribuição unimodal, suas 
curvas de freqüência em relação ao diâmetro vão-se deslocando para a direita à medida que os povoamentos envelhecem e ao mesmo tempo tornam-se mais e mais assimétricas e mais achatadas. Portanto, os objetivos deste estudo foram estudar os efeitos da idade sobre a evolução da curva de distribuição diamétrica para bracatingais nativos da região metropolitana de Curitiba e fazer inferências sobre as mudanças de assimetria e curtose dessas curvas de distribuição diamétrica.

\section{MATERIAL E MÉTODOS}

\subsection{Localização e caracterização da área}

Para a realização desta pesquisa foram utilizados dados provenientes de parcelas permanentes e temporárias, instaladas e medidas em várias localidades da região metropolitana de Curitiba, incluindo 14 municípios e abrangendo uma área de 876.300 ha, dos quais aproximadamente 50.000 ha estão cobertos com bracatingais nativos, ou seja, 5,7\%. As parcelas permanentes foram estabelecidas nos Municípios de Colombo e Bocaiúva do Sul, enquanto as temporárias se localizaram nos Municípios de Bocaiúva do Sul, Colombo, Campina Grande do Sul, Campo Largo, Balsa Nova, Almirante Tamandaré, Rio Branco do Sul, Contenda, Araucária, Piraquara, Quatro Barras, São José dos Pinhais, Quitandinha e Agudos do Sul, todos no Estado do Paraná, Brasil. Esses municípios situam-se entre as latitudes $25^{\circ} 11^{\prime}$ e $25^{\circ} 49^{\prime} \mathrm{S}$ e entre as longitudes $49^{\circ} 05^{\prime}$ e $49^{\circ} 43^{\prime} \mathrm{W}$

\subsection{Base de dados}

Os dados utilizados provieram de um experimento de densidades iniciais delineado em blocos ao acaso, constituído de cinco blocos e quatro tratamentos, perfazendo um total de 20 parcelas permanentes com $325 \mathrm{~m}^{2}$, as quais foram remedidas 4 vezes nas idades aproximadas de 4, 5, 6 e 7,5 anos. A densidade inicial foi reduzida para 2.000, 4.000, 8.000 árvores por hectare; as testemunhas não sofreram nenhum tratamento. Desses cinco blocos, um estava localizado na classe de sítio I, dois na classe II e dois na classe III, de acordo com a classificação de Machado et al. (1997), rearranjada por Tonon (1998). Paralelamente, foram instaladas e medidas 124 parcelas temporárias com 300 m² $^{2} 10$ x 30 $\mathrm{m})$, distribuídas nos vários Municípios da Região Metropolitana, representando os povoamentos de bracatinga sob o regime tradicional de cultivo e manejo, cobrindo idades de 3 a 18 anos e as três classes de sítio. Tais parcelas podem ser consideradas como similares às testemunhas do experimento implantado.

\subsection{Análise do fator idade}

Após a escolha da função $S_{B}$ de Johnson, que foi a de melhor ajuste, mostraram-se quadros de freqüências por classes de diâmetro por hectare, e posteriormente foram traçadas curvas da distribuição diamétrica ao longo das várias idades, sítios e densidades. Para fazer a comparação entre as curvas, ou seja, saber se existe diferença significativa entre elas, aplicouse o teste estatístico qui-quadrado $\left(\chi^{2}\right)$. Nas classes que apresentaram freqüências inferiores a 5 , foi necessário agrupá-las com as classes subseqüentes para poder realizar o teste.

O $\chi^{2}$ (qui-quadrado) é obtido pela expressão:

$$
\chi^{2}=\sum_{\mathrm{i}=1}^{\mathrm{n}} \frac{(\mathrm{n} f i-n F i)^{2}}{(\mathrm{n} F i)},
$$

em que:

$f i=$ probabilidade observada na classe i ;

$F i=$ probabilidade calculada na classe i; e

$n=$ freqüência total.

O teste fem para todas as classes, forneceu um valor calculado, que foi comparado com o tabelado, testado no nível de $1 \%$ de significância.

\subsection{Assimetria e curtose}

As medidas de assimetria e curtose servem para descrever as formas e a evolução das curvas de distribuição. Assimetria é o grau de desvio, ou afastamento da simetria, de uma distribuição de frequiência em relação à curva Normal. A distribuição será simétrica se a média aritmética, moda e mediana forem iguais; nesse caso, o coeficiente de assimetria de Pearson será igual a zero. A distribuição de frequiência será assimétrica quando a média, a mediana e a moda recaírem em pontos diferentes da distribuição, sendo o deslocamento dos pontos para a direita ou para a esquerda. Se uma curva de freqüência de uma distribuição tiver uma "cauda" mais longa à direita da ordenada máxima do que à esquerda, diz-se que a distribuição é assimétrica para a direita, ou que ela tem assimetria positiva. Se ocorrer o inverso, a assimetria é negativa, ou seja, a distribuição é assimétrica para a esquerda (PEREIRA e TANAKA, 1990; SPIEGEL, 1993; CRESPO, 1998).

R. Árvore, Viçosa-MG, v.30, n.5, p.759-768, 2006 
Portanto, em distribuições assimétricas, tem-se:

- Assimetria à direita ou positiva se: moda < mediana $<$ média aritmética.

- Assimetria à esquerda ou negativa se: moda $>$ mediana $>$ média aritmética.

Se o coeficiente de assimetria, em módulo, estiver entre 0,15 e 1 a assimetria é considerada moderada e se o mesmo for maior que 1 , a assimetria será forte.

Já a curtose é o grau de achatamento ou elevação relativa de uma distribuição, considerada usualmente em relação à distribuição normal. Para a curva Normal, o coeficiente de curtose será zero e, se este for positivo, a distribuição será mais elevada e, se for negativo, indicará uma curva mais achatada. Os coeficientes de assimetria e de curtose foram calculados seguindose a metodologia recomendada por Spiegel (1993).

Crespo (1998) e Pereira e Tanaka (1990) definiram três tipos de curvas em relação à curtose:

- Leptocúrtica é a distribuição que tem um pico relativamente alto, com excesso negativo, ou seja, coeficiente de curtose $<0,263$.

- Platicúrtica é a curva que apresenta um topo mais achatado, com excesso positivo, isto é, coeficiente de curtose $>0,263$.

- Mesocúrtica é a curva intermediária, com coeficiente de curtose $=0,263$.

\section{RESULTADOS E DISCUSSÃO}

Para avaliar a evolução da distribuição diamétrica ao longo do tempo e o efeito da idade sobre as curvas de distribuição diamétrica, estimadas pela função $S_{B}$ de Jonhson, foram traçadas curvas para cada idade de medição das parcelas permanentes usando-se a função $\mathrm{S}_{\mathrm{B}}$ de Jonhson previamente ajustada para cada uma das combinações de dados (BARTOZECK, 2000). Para essa análise foram fixados os fatores sítio e densidade, variando-se somente a idade.

Verificou-se com o passar do tempo aumento na amplitude total dos diâmetros, o número de árvores diminuiu nas menores classes e aumentou nas maiores e, além disso, as curvas se movimentaram para a direita. Segundo os índices de assimetria e curtose na pesquisa de Bartozeck (2000), observou-se distribuição assimétrica à direita ou positiva para idades 3,9 e 4,8 nas densidades- testemunha e 8.000 árvores/ha e um excesso negativo quanto à curtose em comparação com a curva normal (leptocúrticas). Quanto às outras densidades dessas medições, observou-se assimetria negativa (ou à esquerda); quanto à curtose, elas foram platicúrticas, ou seja, mais achatadas. Mas todas as curvas apresentaram assimetria moderada (coeficiente de assimetria entre 0,15 e 1 . Portanto, com o aumento da idade as curvas que eram assimétricas à direita passaram a ser mais assimétricas à esquerda do que à direita e se tornam mais achatadas (Figura 1).

Rochadeli (1997) também verificou, em bracatingais da porção norte da Região Metropolitana de Curitiba, que nas menores idades a assimetria à direita é mais significativa que nas maiores idades, além do que nessas idades algumas parcelas apresentaram certo achatamento nas suas curvas de freqüência. Da mesma forma, as maiores classes diamétricas apresentaram um desvio menor no que se refere à diferença entre os dados observados e esperados, enquanto as classes médias e inferiores apresentaram desvio maior.

Essa evolução de assimetria e curtose também foi verificada por Scolforo (1990) para povoamento de Pinus caribaea var. hondurensis com índice de sítio de 29 m, 500 árvores/ha, nas idades 15 a 19 anos.

Nos sítios II e III, as tendências encontradas não foram diferentes do sítio I, nas várias densidades; no entanto, como esses sítios apresentam parcelas com mais idades, foi mais fácil e evidente verificar os efeitos da idade nas curvas de distribuição diamétrica, visto que mais idades aparecem para reforçar o que já foi encontrado no sítio I (Figuras 2 e 3 ).

Nas primeiras idades do povoamento, a frequiência estimada/ha é maior nas menores classes diamétricas, porém essa vai diminuindo com o aumento das idades, deslocando a curva para a direita, com assimetrias positivas ou à direita, com um alongamento na cauda da curva para esse lado. No entanto, uma assimetria negativa ou à esquerda foi verificada nas curvas das idades 4,1 anos para 2.000 e 4.000 árv./ha e 5,0 anos para a densidade de 4.000 árv./ha. Os achatamentos foram bem evidenciados das menores para as maiores idades, conforme mostrdoa as Figuras 2 e 3. Os índices de assimetria e curtose encontrados por Bartozeck (2000) ratificaramm essas análises visuais, podendo-se concluir que todas as curvas apresentaram assimetria moderada (coeficiente de assimetria entre 0,15 e 1 ). 

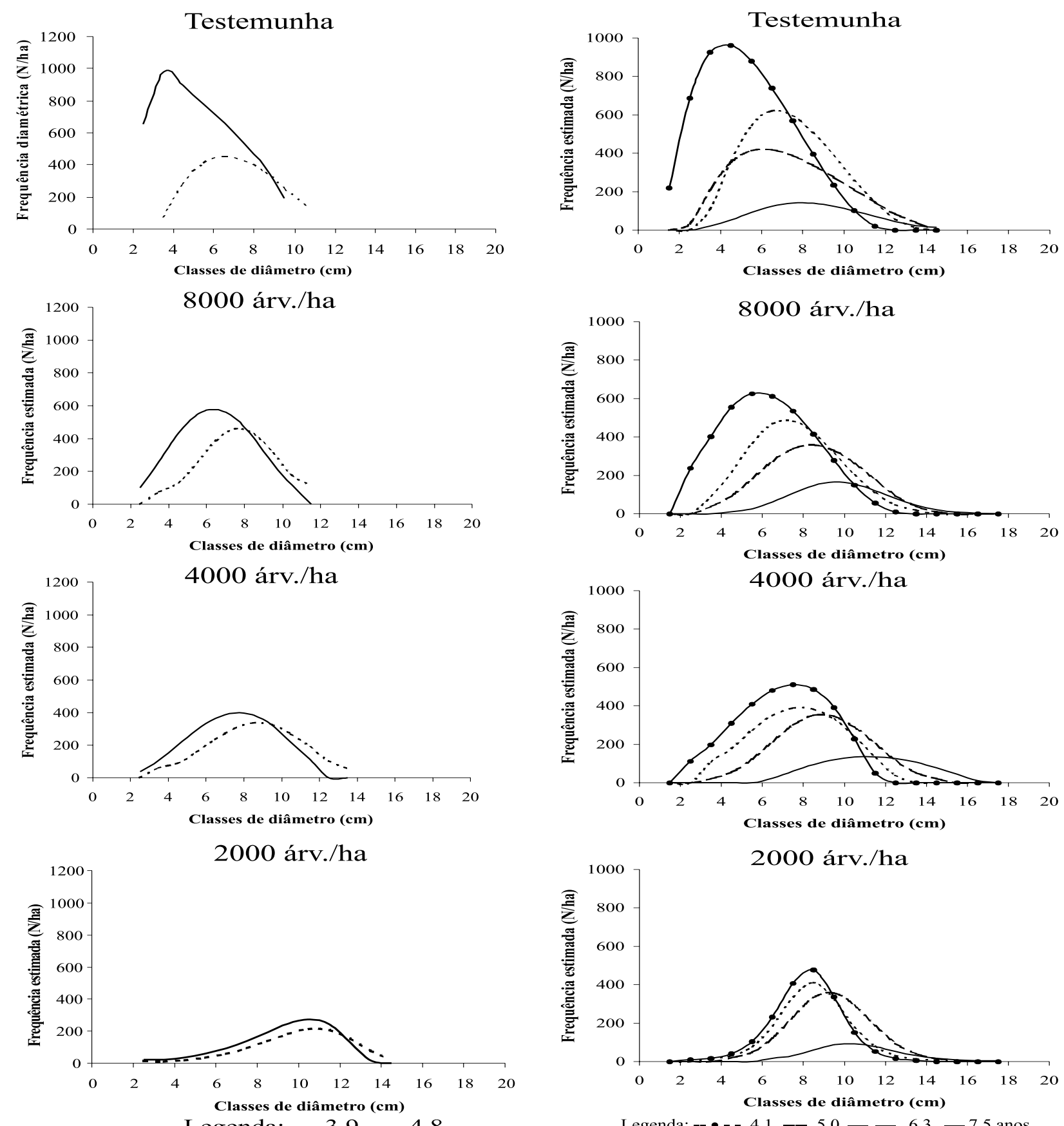

Figura 1 - Evolução das frequiências estimadas por hectare pela função $S_{B}$, nas parcelas do sítio I, nas idades de 3,9 e 4,8 e nos quatro tratamentos de densidade inicial.

Figure 1-Evolution of the estimated frequencies per hectare by the adjusted $S_{B}$ function for the plots on site I at ages 3.9 and 4.8 years, and for the 4 initial density treatments.

Figura 2 - Evolução das freqüências estimadas por hectare pela função $S_{B}$ nas parcelas do sítio II, idades de 4,1 a 7,5 anos, nos quatro tratamentos de densidade inicial.

Figure 2-Evolution of estimated frequencies per hectare by the SB function for the plots on Site II and ages ranging from 4.1 to 7.5 years, for the 4 initial density treatments.

R. Árvore, Viçosa-MG, v.30, n.5, p.759-768, 2006 

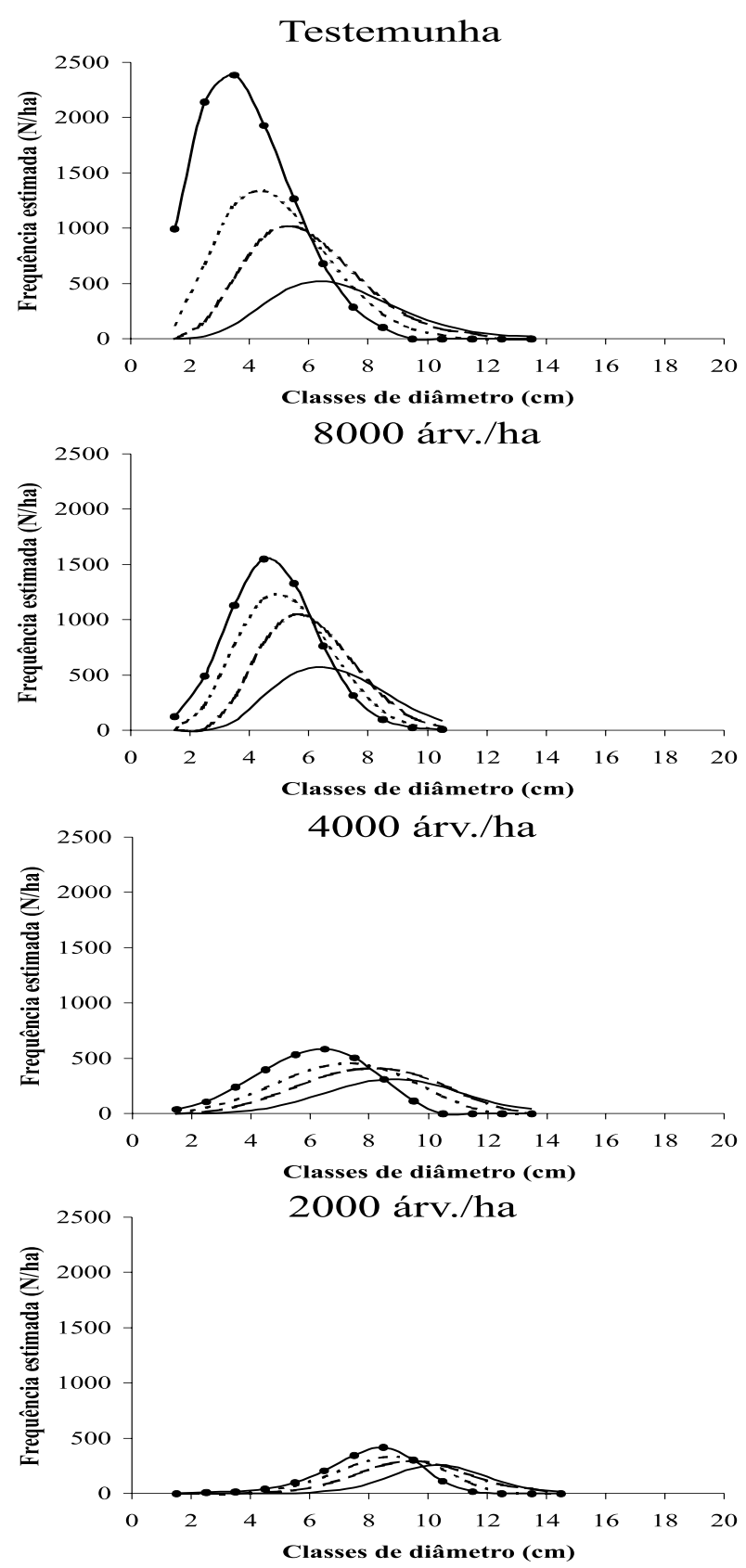

Legenda: -- - 4,1 -- 5,0_- 6,3 - 7,5 anos

Figura 3 - Evolução das freqüências estimadas por hectare pela função $S_{B}$, nas parcelas do sítio III, idades de 4,2 a 7,6 anos, nos 4 tratamentos de densidade inicial.

Figure 3 - Evolution of estimated frequencies per hectare by the adjusted $S B$ function for the plots on Site III and ages ranging from 4.2 to 7.6 years, for the 4 initial density treatments.
Visualmente, pode-se verificar que há uma diferença bem aparente entre as curvas mostradas nas Figuras 1,2 e 3 , pois o diâmetro tende a crescer com o aumento das idades, deslocando a curva ao longo das classes diamétricas, pois há mudança de árvores de uma classe para outra ao mesmo tempo em que há mortalidade de árvores, reduzindo a freqüência total ao longo do tempo. Para comprovar, estatisticamente, a diferença da forma das curvas entre as várias combinações de idade, as classes com freqüências inferiores foram agrupadas. Após o agrupamento dessas classes, aplicouse o teste $\chi^{2}$, conforme mostrado no Quadro 1 .

Os valores calculados foram, então, comparados com os valores tabelados de $\chi^{2}$. Esta análise comprovou que há diferença significativa entre os valores calculados para $1 \%$ de significância. Em um mesmo nível de significância, quanto maior o valor do GL, maior o valor tabelado. Essa diferença comprovou o avaliado visualmente, ou seja, uma grande diferença entre as curvas e um forte efeito da idade na distribuição diamétrica.

O teste Qui-quadrado no sítio II se encontra no Quadro 2. Foi observado, nesse quadro, que, quanto maior a diferença entre duas idades comparadas, maior o valor do $\chi^{2}$. Esses valores foram significativos a $1 \%$ nas idades nas várias densidades dos sítios II e III (Quadros 2 e 3).

Os resultados apresentados comprovaram a teoria a respeito do efeito da variável idade. As diferenças significativas entre idades sobre a distribuição diamétrica eram esperadas. Os comportamentos das curvas no presente trabalho, ao se avaliarem as idades, estão em conformidade com o trabalho de Clutter e Benett (1965), que observaram que as curvas de distribuição diamétrica para Pinus elliottii se deslocaram para a direita em função do fator idade, ocorrendo decréscimo no número de árvores nas classes inferiores e aumento no número de árvores nas classes superiores.

Quadro 1 - Valores do teste $\chi^{2}$ (Qui-quadrado) envolvendo a combinação das idades de 3,9 e 4,8 anos, nos 4 tratamentos de densidade inicial, para avaliação do fator idade - Sítio I

Table 1 -Values of $\chi^{2}$ (Chi-square) for combinations of the ages 3.9 and 4.8, on Site I, for the 4 initial density treatments to evaluate the age effect

\begin{tabular}{lcccc}
\hline & Testemunha & 2000 & 4000 & 8000 \\
& & Árv./ha & Árv./ha & Árv./ha \\
\hline$\chi^{2}$ & 37000,8 & 237,4 & 642,4 & 2324,0 \\
GL & 6 & 11 & 8 & 7 \\
\hline
\end{tabular}


Quadro 2 - Valores do teste $\chi^{2}$ envolvendo a combinação das idades de 4,1 a 7,5 anos, nos quatro tratamentos de densidade inicial, para avaliação do fator idade - Sítio II

Table 2 -Values of $\chi^{2}$ between ages 4.1 and 7.5 years, on site II, for the 4 initial density treatments, to evaluate age effects

\begin{tabular}{|c|c|c|c|c|c|c|}
\hline \multicolumn{7}{|c|}{ Idades (anos) } \\
\hline \multicolumn{7}{|c|}{ Testemunha } \\
\hline & $4,1-5,0$ & $4,1-6,3$ & $4,1-7,5$ & $5,0-6,3$ & $5,0-7,5$ & $6,3-7,5$ \\
\hline$\chi^{2}$ & 343877,1 & 2208,9 & 11714,2 & 417,5 & 11646,4 & 10821,0 \\
\hline \multicolumn{7}{|c|}{2000 Árv./ha } \\
\hline & $4,1-5,0$ & $4,1-6,3$ & $4,1-7,5$ & $5,0-6,3$ & $5,0-7,5$ & $6,3-7,5$ \\
\hline$\chi^{2}$ & 89,5 & 753,3 & 18678,9 & 307,9 & 10193,5 & 5875,7 \\
\hline \multicolumn{7}{|c|}{4000 Árv./ha } \\
\hline & $4,1-5,0$ & $4,1-6,3$ & $4,1-7,5$ & $5,0-6,3$ & $5,0-7,5$ & $6,3-7,5$ \\
\hline$\chi^{2}$ & 817,2 & 5353,5 & 106902,0 & 1139,3 & 36380,9 & 8787,8 \\
\hline \multicolumn{7}{|c|}{8000 Árv./ha } \\
\hline & $4,1-5,0$ & $4,1-6,3$ & $4,1-7,5$ & $5,0-6,3$ & $5,0-7,5$ & $6,3-7,5$ \\
\hline$\chi^{2}$ & 5101,7 & 11478,9 & 20465,6 & 636,9 & 17561,1 & 4119,9 \\
\hline
\end{tabular}

Ao comparar os valores calculados de $\chi^{2}$ constantes no Quadro 2 com os valores tabelados, verificou-se que a idade apresentou efeitos altamente significativos sobre a curva de distribuição diamétrica para o nível de significância de 0,01.

Essa mesma evolução foi encontrada por Arce et al. (1999) para Populus deltoides Marsh, nas curvas de distribuição diamétrica estimadas pela função Weibull para as medições de 1987 até 1995, com deslocamentos e achatamentos bem destacados.

Um enfoque bastante importante a ser avaliado é a correlação dos parâmetros da função de distribuição com a idade, uma vez que, quanto maiores estas forem, maiores serão as chances de sucesso por ocasião do uso da distribuição para fins de prognose.

Os efeitos dos parâmetros $\delta$ e $\gamma$ da função $S_{B}$ são distintamente diferentes, sendo que $\delta$ afeta a curtose e $\gamma$, a assimetria. Através de uma análise de regressão linear simples pôde-se observar a baixa correlação dos parâmetros dessa função com a idade. A curtose apresentou uma correlação de 0,2563, e a assimetria de 0,4135 . Os valores do estimador $\delta$ foram inconstantes em função da idade, subindo e descendo sem uma correlação definida com a idade. Mas a maior correlação encontrada foi para o parâmetro amplitude $(\lambda)$, com 0,5540 .

Quadro 3 - Valores do teste $\chi^{2}$ envolvendo a combinação das idades de 4,2 a 7,6 anos, nos quatro tratamentos de densidade inicial, para avaliação do fator idade - Sítio III

Table $3-\chi^{2}$ values including combinations of the 4 initial density treatments of ages from 4.2 to 7.6 on site III, to evaluate age effects

\begin{tabular}{|c|c|c|c|c|c|c|}
\hline \multicolumn{7}{|c|}{ Idades (anos) } \\
\hline \multicolumn{7}{|c|}{ Testemunha } \\
\hline & $4,2-5,0$ & $4,2-6,3$ & $4,2-7,5$ & $5,4-6,3$ & $5,4-7,6$ & $6,3-7,6$ \\
\hline$\chi^{2}$ & 10874,0 & 62545,2 & 461302,5 & 3715,0 & 39353,6 & 4301,6 \\
\hline \multicolumn{7}{|c|}{2.000 Árv/ha } \\
\hline & $4,2-5,0$ & $4,2-6,3$ & $4,2-7,5$ & $5,4-6,3$ & $5,4-7,6$ & $6,3-7,6$ \\
\hline$\chi^{2}$ & 290,2 & 1299,3 & 8857,9 & 337,5 & 3804,9 & 1127,8 \\
\hline \multicolumn{7}{|c|}{ 4.000 Árv/ha } \\
\hline & $4,2-5,0$ & $4,2-6,3$ & $4,2-7,5$ & $5,4-6,3$ & $5,4-7,6$ & $6,3-7,6$ \\
\hline$\chi^{2}$ & 870,0 & 2461,6 & 13415,7 & 436,4 & 3340,8 & 850,6 \\
\hline \multicolumn{7}{|c|}{8.000 Árv/ha } \\
\hline & $4,2-5,0$ & $4,2-6,3$ & $4,2-7,5$ & $5,4-6,3$ & $5,4-7,6$ & $6,3-7,6$ \\
\hline$\chi^{2}$ & 2005,4 & 23632,4 & 395865,7 & 2810,7 & 20069,8 & 2463,7 \\
\hline
\end{tabular}


Couto (1980), trabalhando com plantios de Pinus caribaea, encontrou resultados similares, em que os valores do estimador $\delta$ (curtose) da função $S_{B}$ foram inconstantes em função da idade, subindo e descendo sem uma correlação definida com a idade, independentemente dos tratamentos aplicados, com fertilização e sem fertilização. O estimador $\gamma$ (assimetria) apresentou uma tendência de aumentar com a idade, para os plantios sem tratamento, o que não houve para os valores nos plantios com tratamento.

Tabai (1999) estudou a distribuição diamétrica de Pinus taeda através da função $\mathrm{S}_{\mathrm{B}}$ e, também, avaliou a correlação dos parâmetros com a idade, concluindo que o parâmetro locação $(\varepsilon)$ é altamente correlacionado com a idade; o parâmetro escala $(\lambda)$ também; e o parâmetro assimetria $(\gamma)$ tem correlação significativa usando o método da Moda. Para os outros métodos, houve grande flutuação nos valores de correlação deste com a idade. O parâmetro curtose $(\delta)$ é o que menos apresentou correlação com a idade.

\subsection{Parcelas temporárias}

O mesmo procedimento efetuado com as parcelas permanentes foi realizado para as temporárias. Com a função $S_{B}$ foram traçadas as curvas da distribuição diamétrica para cada combinação de sítio e idade. No entanto, a ausência de informação nas classes abaixo de $5 \mathrm{~cm}$ de diâmetro limitou as curvas nessas classes.

Para o ajuste das funções nas parcelas temporárias foi necessário agrupar os dados destas com os dados das testemunhas das permanentes, pois agregaram dados nas idades em que estavam faltando para a construção das curvas de distribuição diamétrica, devido a uma limitação na medição das parcelas temporárias, em que o diâmetro mínimo de medição para algumas parcelas foi de $5 \mathrm{~cm}$. Com esse procedimento, as curvas deixaram de ficar incompletas nas idades iniciais, em que ocorrem os menores diâmetros. No entanto, na idade de 3 anos não foi possível suprir essa falta, porque nas parcelas permanentes a idade mais nova em que foram medidos os diâmetros correspondeu à de 3,9 anos, ou seja, quase 4 anos.

Após a união dos dados das parcelas temporárias com as testemunhas das permanentes e do ajuste através da função $S_{B}$, traçaram-se as curvas para as várias idades dos três sítios, usando a função $S_{B}$. As curvas apresentaram o mesmo comportamento verificado nas parcelas permanentes, movendo-se para a direita, com assimetria positiva à direita para a maioria das idades, à exceção da parcela com idade de 11 anos pertencente ao sítio II e idade de 10 anos no sítio III. Também houve achatamento acentuado ao longo do tempo até alcançar quase o máximo na idade de 18 anos, conforme pode ser observado no trabalho de Bartoszeck (2000).

No Quadro 4, podem-se verificar as freqüências estimadas para as várias classes diamétricas para as parcelas temporárias do sítio II com os dados agregados das testemunhas das parcelas temporárias nas idades de 4 e 5 anos. Os quadros de freqüências nos sítios I e III podem ser encontradas em Bartoszeck (2000).

Foi verificado pelo teste qui-quadrado diferença significativa entre as curvas da distribuição nas várias idades, confirmando o efeito encontrado nas parcelas permanentes.

Quadro 4 - Número de árvores estimadas por hectare através da função $S_{B}$, por classe diamétrica, nas diferentes idades das parcelas temporárias - Sítio II

Table 4 - Number of trees estimated per hectare by function $S_{B}$, per diameter class and per different ages of site II

\begin{tabular}{|c|c|c|c|c|c|c|c|}
\hline \multirow{2}{*}{$\begin{array}{l}\text { Centro de classe } \\
\text { diamétrica }(\mathrm{cm})\end{array}$} & \multicolumn{6}{|c|}{ Idades $(\mathrm{cm})$} & \multirow[b]{2}{*}{18} \\
\hline & 4 & 5 & 6 & 7 & $8-9$ & $11-12$ & \\
\hline 1,5 & 144,4 & 0,2 & - & - & - & - & - \\
\hline 2,5 & 369,1 & 8,2 & 9,7 & - & - & - & - \\
\hline 3,5 & 585,7 & 75,4 & 33,3 & 4,1 & - & 1,4 & - \\
\hline 4,5 & 686,7 & 254,4 & 100,3 & 49,0 & - & 5,7 & - \\
\hline 5,5 & 671,6 & 456,0 & 215,1 & 141,6 & 100,9 & 16,4 & - \\
\hline 6,5 & 582,8 & 533,8 & 334,3 & 225,1 & 149,3 & 34,0 & 4,7 \\
\hline 7,5 & 464,2 & 461,3 & 393,7 & 265,3 & 200,6 & 55,6 & 2,4 \\
\hline 8,5 & 346,1 & 317,7 & 371,0 & 263,0 & 222,9 & 76,1 & 3,6 \\
\hline
\end{tabular}

R. Árvore, Viçosa-MG, v.30, n.5, p.759-768, 2006 


\begin{tabular}{|c|c|c|c|c|c|c|c|}
\hline \multirow{2}{*}{$\begin{array}{l}\text { Centro de classe } \\
\text { diamétrica }(\mathrm{cm})\end{array}$} & \multicolumn{7}{|c|}{ Idades $(\mathrm{cm})$} \\
\hline & 4 & 5 & 6 & 7 & $8-9$ & $11-12$ & 18 \\
\hline 9,5 & 244,4 & 183,2 & 294,6 & 233,0 & 220,3 & 90,6 & 5,4 \\
\hline 10,5 & 164,6 & 91,4 & 206,0 & 190,7 & 201,4 & 96,9 & 8,0 \\
\hline 11,5 & 106,0 & 40,4 & 131,3 & 146,7 & 174,5 & 95,1 & 11,5 \\
\hline 12,5 & 65,4 & 16,0 & 78,3 & 107,3 & 145,2 & 87,2 & 16,2 \\
\hline 13,5 & 38,7 & 5,7 & 44,6 & 75,0 & 117,3 & 75,7 & 22,1 \\
\hline 14,5 & 21,8 & 2,6 & 24,6 & 50,2 & 92,4 & 62,8 & 28,8 \\
\hline 15,5 & 11,7 & - & 13,3 & 32,2 & 71,4 & 50,1 & 35,7 \\
\hline 16,5 & 10,9 & - & 7,1 & 19,7 & 54,2 & 38,8 & 41,8 \\
\hline 17,5 & - & - & 3,7 & 11,5 & 40,5 & 29,3 & 46,0 \\
\hline 18,5 & - & - & 2,0 & 6,4 & 29,9 & 21,7 & 47,6 \\
\hline 19,5 & - & - & 1,0 & 6,0 & 21,8 & 15,7 & 46,2 \\
\hline 20,5 & - & - & 0,5 & - & 15,6 & 11,2 & 42,4 \\
\hline 21,5 & - & - & 0,6 & - & 11,1 & 7,9 & 36,9 \\
\hline 22,5 & - & - & - & - & 7,8 & 5,5 & 30,7 \\
\hline 23,5 & - & - & - & - & 5,4 & 3,8 & 24,6 \\
\hline 24,5 & - & - & - & - & 3,7 & 2,6 & 19,1 \\
\hline 25,5 & - & - & - & - & 2,5 & 1,8 & 14,5 \\
\hline 26,5 & - & - & - & - & 1,6 & 1,2 & 10,8 \\
\hline 27,5 & - & - & - & - & 2,8 & 0,8 & 8,0 \\
\hline 28,5 & - & - & - & - & - & 1,7 & 5,8 \\
\hline 29,5 & - & - & - & - & - & - & 4,2 \\
\hline 30,5 & - & - & - & - & - & - & 3,0 \\
\hline 31,5 & - & - & - & - & - & - & 2,2 \\
\hline 32,5 & - & - & - & - & - & - & 1,6 \\
\hline 33,5 & - & - & - & - & - & - & 4,2 \\
\hline
\end{tabular}

\section{CONCLUSÕES}

Os resultados gerados das diferentes combinações da idade dentro de diferentes densidades e sítios estão em conformidade com o desenvolvimento biológico esperado. O teste qui-quadrado utilizado para fazer a comparação entre as curvas de distribuição diamétrica mostrou que há diferenças significativas delas com relação aos efeitos do fator idade.

Para o fator idade, ocorreu decréscimo do número de árvores nas classes inferiores e aumento do número de árvores nas classes superiores, deslocando-se a curva para a direita com um acentuado achatamento (curtose) ao longo do tempo; além disso, verificaramse assimetrias moderadas das curvas nas várias idades.

\section{REFERÊNCIAS BIBLIOGRÁFICAS}

ARCE, J. E, et al. Modelos dinámicos de distribuciones diamétricas en Populus deltoides Marsh. In: JORMA VI - JORNADAS DE MEDIO AMBIENTE. STATISTICS AND ENVIRONMENT, 1999. La Plata, Argentina. Actas del congreso. La Plata: Universidad de Cadiz, España e Universidad de La Plata, 1999. p. 21-32.
BARTOSZECK, A.C.P.S. Evolução da distribuição diamétrica e da relação hipsométrica em função dos fatores idade, sítio e densidade inicial em bracatingais da região metropolitana de Curitiba. 2000. 214 f. Dissertação (Mestrado em Engenharia Florestal). Universidade Federal do Paraná, Curitiba, 2002.

CLUTTER, J. L.; BENETT, F.A. A diameter distributions in old field slash pine plantations. Georgia Forest Research Council Report, n. 13, p. 1-9, 1965.

COUTO, H.T.Z. Distribuição de diâmetros em plantações de Pinus caribaea Morelet var caribaea. 1980. 79 f. Tese (Livre Docência) Escola Superior de Agricultura "Luiz de Queiroz", Piracicaba, 1980

CRESPO, A.A. Estatística Fácil. 16. ed. São Paulo: Saraiva, 1998. 207 p.

R. Árvore, Viçosa-MG, v.30, n.5, p.759-768, 2006 
MACHADO, S.A.; BACOVIS, R.;

MARQUESINI, L.C.P.T. Estudo das funções de distribuição diamétrica das árvores desbastadas em plantações de Pinus taeda no Estado do Paraná. In: CONGRESSO FLORESTAL BRASILEIRO, 6., 1990. Campos do Jordão.Anais... Campos do Jordão: 1990. v.3, p. 145-152.

MACHADO, S.A. et al. Classificação de sítio para bracatingais na região metropolitana de Curitiba. Boletim de Pesquisa

Florestal, Colombo, n. 35, p. 21-37, 1997.

PEREIRA, W.; TANAKA, O.K. Estatística conceitos básicos. 2. ed. São Paulo: Makron Books, 1990. 371 p.

ROCHADELLI, R. Contribuição sócioeconômica da Bracatinga (Mimosa Scabrella Bentham) na Região Metropolitana de Curitiba-Norte (RMC-N). 1997. 83 f. Dissertação (Mestrado em Ciências Florestais) - Universidade Federal do Paraná, Curitiba, 1997.
SCOLFORO, J.R. Sistema integrado para predição e análise presente e futura de crescimento e produção, com otimização de remuneração de capitais, para Pinus caribaea var. hondurensis. 1990. 290 f. Tese (Doutorado em Ciências Florestais) Universidade Federal do Paraná, Curitiba, 1990.

SPIEGEL, M. R. Estatística. São Paulo: Makron Books, 1993. 643 p.

TABAI, F.C.V. O estudo da acuracidade da distribuição $S_{B}$ para representar a estrutura diamétrica de Pinus taeda, através de cinco métodos de ajuste. 1999. 55 f. Dissertação (Mestrado em Ciências Florestais). Universidade Federal de Lavras, Lavras, 1999.

TONON, A.E.N. Efeitos da densidade inicial e do sítio sobre o crescimento e a produção de bracatingais da região metropolitana de Curitiba. 1998. 209 f. Dissertação (Mestrado em Manejo Florestal) Setor de Ciências Agrárias, Universidade Federal do Paraná, Curitiba, 1998. 